University of Nebraska - Lincoln

DigitalCommons@University of Nebraska - Lincoln

Publications from USDA-ARS / UNL Faculty

U.S. Department of Agriculture: Agricultural

Research Service, Lincoln, Nebraska

2002

Impact of Egg Storage on Embryo Development

M. R. Bakst

USDA, murray@lpsi.barc.usda.gov

V. Akuffo

US Department of Agriculture

Follow this and additional works at: https://digitalcommons.unl.edu/usdaarsfacpub

Part of the Agricultural Science Commons

Bakst, M. R. and Akuffo, V., "Impact of Egg Storage on Embryo Development" (2002). Publications from USDA-ARS / UNL Faculty. 628.

https://digitalcommons.unl.edu/usdaarsfacpub/628

This Article is brought to you for free and open access by the U.S. Department of Agriculture: Agricultural Research Service, Lincoln, Nebraska at DigitalCommons@University of Nebraska - Lincoln. It has been accepted for inclusion in Publications from USDA-ARS / UNL Faculty by an authorized administrator of DigitalCommons@University of Nebraska - Lincoln. 


\title{
Impact of Egg Storage on Embryo Development
}

\author{
M.R. Bakst and V. Akuffo
}

Germplasm and Gamete Physiology Laboratory, Agricultural Research Service, USA Department of Agriculture, Beltsville Agricultural Research Center, Beltsville, Maryland, USA

\begin{abstract}
1. New information is introduced and other information reviewed regarding the impact of egg storage on the integrity of the avian embryo.

2. Morphologically, the blastoderm from an egg which has been stored more than 10 days is often asymmetrical and may have an attenuated appearance.

3. Fresh egg breakouts coupled with the perivitelline layer sperm-hole determination procedure provide detailed information on the male's contribution to overall fertility.

4. The biological basis for embryonic mortality in eggs stored for longer than 10 days remains the subject of speculation.
\end{abstract}

\section{INTRODUCTION}

Prolonged cool egg storage, a common commercial practice with turkey eggs in the USA, has a detrimental effect on hatchability (Asmundson, 1947; Arora and Kosin, 1966a,b; Christensen and Bagley, 1989; Butler 1991) and therefore, is of considerable concern to commercial turkey hatchery operators. In fact, a rule-of-thumb in the hatchery is that for every day after 10-days of storage, hatchability will decrease by $1 \%$. Studies aimed at defining the optimum conditions for cool egg storage that maximize hatchability have been conducted (Foulkes, 1990; Proudfoot and Hamilton, 1990; Butler, 1991; Scott and Mackenzie, 1993). Notwithstanding this, the national hatchability rate is not increasing and it has been suggested that hatchability is decreasing. It has been shown that temperature, in concert with humidity, duration of storage, and egg orientation play major roles in influencing embryo development during cool storage and incubation (Romanoff, 1960; Landauer, 1967; Proudfoot, 1969; Christensen and Bagley, 1989; Proudfoot and Hamilton, 1990; Butler, 1991). The temperature at which embryo development is reversibly suppressed, referred to as physiological zero, has long been considered to be $20^{\circ}$ to $21^{\circ} \mathrm{C}$ (Edwards, 1902), although higher tempera- tures $\left(26.7^{\circ} \mathrm{C}\right.$, Funk and Biellier, $1944 ; 28^{\circ}$ to $29^{\circ} \mathrm{C}$, Lundy, 1969) have also been suggested. Plausible explanations for this wide range of temperatures describing physiological zero include the following: the method of determining the actual stage of development of the embryo; a wide variation in the stage of development of the blastoderm in fresh oviposited eggs within the same genetic strain; and, differences in genetic strain.

In this work, we review some previously published and present new observations describing the impact of cool egg storage on the blastoderm. By employing new techniques and procedures, our observations have and will provide better insight into the adverse effects of long-term cool egg storage. More specifically, the turkey embryo staging procedure (Gupta and Bakst, 1994) permitted the discrimination of extremely subtle developmental differences prior to gastrulation between turkey embryos. Furthermore, immunocytochemical and molecular probes provide the means to localize specific cellular and extracellular responses to the treatments. Work such as that presented herein will provide fundamental and applied information which may have a substantial impact on turkey egg handling and management procedures currently used, much of which is based on contradictory observations.

*To whom correspondence should be addressed at: E-mail: murray@lpsi.barc.usda.gov

This article is a U.S. government work, and is not subject to copyright in the United States. 


\section{RESULTS AND DISCUSSION}

\section{Overview}

One of the objectives of our research program has been to determine the biological ramifications of cool egg storage on the blastoderm structure, function, and subsequent development. The following paper is a brief summary of published information as well as new observations on the impact of short (4 days or less) and long term storage (greater than 10 days) on blastoderm integrity. A brief review of the literature regarding the impact of egg storage on embryo viability and the embryo-staging techniques used by our laboratory will provide the reader with the background necessary to understand the problems to be addressed and the methodology employed.

In commercial turkey hatchery practice, eggs are usually stored around $18^{\circ} \mathrm{C}$, with lower temperatures recommended for longer durations (Kirk et al., 1980; Proudfoot and Hamilton, 1990). Arora and Kosin (1966a) described the impact of prolonged storage of chicken and turkey. More recently, Fasenko et al., (1992) reported that chicken eggs stored for 1 to 21 days at $14^{\circ} \mathrm{C}$ did not advance developmentally. However, Fasenko et al., (1992) did note that the incidence of embryonic mortality increased when egg storage was 14 or 21 days. Scott and Mackenzie (1993) also found that there was no effect of holding time (24 hours) and temperature $\left(18^{\circ}\right.$ or $30^{\circ} \mathrm{C}$ ) on embryo development. However, others noted that there was a significant advancement in the stage of embryo development if the eggs were held in the nest for 6 to $8 \mathrm{hr}$ before storage at $13.8^{\circ} \mathrm{C}$ (Jones, 1986; Fasenko et al., 1991). These appear to be contradictory observations.

With respect to the turkey, Bakst and Gupta (1997) noted that whether stored for 6 hours at room temperature or 7 or 14 days at $18^{\circ} \mathrm{C}$, embryonic development advanced slightly to the same stage. Morphologically, this developmental advance is quite subtle and would not be easily discernible to the untrained observer. It is characterized by an increase in the surface area of the area pellucida and an attenuation of the area opaca (Stage VII to Stage VIII; see Gupta and Bakst, 1993). Except for the works of Fasenko et al., (1992) and Bakst and Gupta $(1997 ; 1998)$, previous investigators failed to use an objective embryo staging procedure to describe the developmental status of the embryo.

\section{Embryo staging}

Staging procedures are extremely important in that they provide objective, defined, and standardized descriptions of the morphogenetic development of the embryo. To appreciate the stage-by-stage progression described in these procedures one should refer to Eyal-Giladi and Kochav (1976). These authors were the first to describe the morphogenetic events from the initial cleavage of the fertilised germinal disc in the oviducal egg mass through completion of the hypoblast during the early stages of incubation. In the EyalGiladi and Kochav staging procedure, a Stage I embryo is a blastodisc with less than 5 or so cleavage divisions, while a Stage XIV embryo has a completed hypoblast. Some years earlier, Hamburger and Hamilton (1951) described a staging procedure for development of the chick embryo from oviposition to hatch. It is generally accepted that the Stage 2 Hamburger and Hamilton embryo is the equivalent to the Stage XIV Eyal-Giladi and Kochav.

Gupta and Bakst (1993) concluded that the staging procedure described by Eyal-Giladi and Kochav (1976) for the chicken embryo was not directly applicable to the turkey embryo. Based on their observations, Gupta and Bakst (1993) proposed an 11-stage series describing the sequence of morphogenetic events from first cleavage to hypoblast formation in the turkey embryo. Based on this staging procedure, the majority of fresh laid eggs when broken-out within 1 hour after oviposition, possessed Stage VII embryos. Here the blastoderm is characterized by a discernible area opaca, area pellucida, and area alba. The area alba, which is not observed in the chicken embryo, is a whitish area consisting of large diameter blastodermal cells, situated nearly in the middle of the area pellucida (Figure 1). Interestingly, there is still considerable eggto-egg variation in the appearance of the blastoderm at oviposition within strains as well as within a clutch of eggs. The impact of egg storage at or below physiological zero on the embryo and individual blastodermal cells both at a cellular and molecular level remains unknown.

\section{Turkey embryo morphology before and after cool egg storage}

As noted in the previous section nearly all blastoderms examined at the time of breakout were in Stage VII or VIII. Regardless of the length of time of storage, pre- 


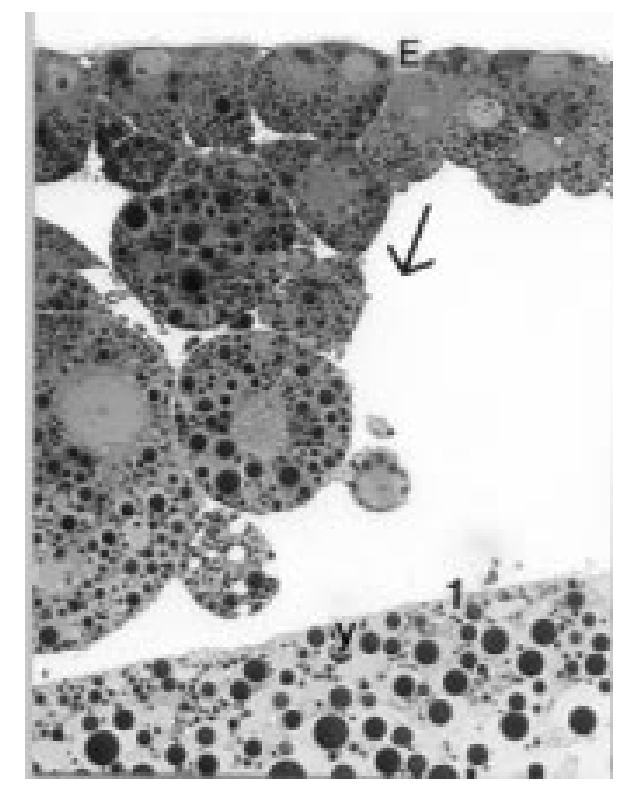

Fig. 1. This histological section reveals a portion of giant blastodermal cell which constitutes part of the area alba. Budding from the epiblast, here consisting of cuboidal cells, are polyingressing cells. Absent from this preparation is the perivitelline layer. However, white yolk is observed forming the ventral boundary of the subgerminal cavity. The long axis of the giant cell nucleus is about $11 \mu \mathrm{m}$.

incubation development of turkey embryos advanced when compared to unstored fresh laid eggs (Bakst and Gupta, 1997). The development, which to the untrained observer would be insignificant, was found to be significant when evaluated using the embryonic staging procedure. As expected, there was a positive linear relationship between loss of egg weight and the duration of storage.

Embryos from eggs which had been stored longer than 5 days at $15^{\circ}$ to $18^{\circ} \mathrm{C}$ and at room temperature for more than 36 hours often had an anomalous appearance (Compare Figures 2a and $2 \mathrm{~b}$ ). This varied from an asymmetrical blastoderm to enlarged blastoderms with an attenuated area pellucida. Small vacuoles occasionally appeared in the periphery of the area opaca. Histologically, such aberrant morphology was characterized by the following: absence of or reduced extent of the subgerminal cavity; a compact, somewhat disorganized epiblast; flocculent material surrounding the blastodermal cells, which occupied the space between the perivitelline layer and yolk; and, a ruffled outer perivitelline layer (Figure 3), which is characteristically found with mottled yolks (Fasenko, 1995). Of particular interest was the appearance of the epiblast in eggs stored longer than 10 days. In fresh laid eggs, the epiblast, which forms the dorsal boundary of the subgerminal cavity, consists of columnar and high cuboidal cells one to three cells thick. After storage, the cells no longer had a distinct high cuboidal appearance and, in fact, seemed to be smaller in volume and their nuclei less prominent.
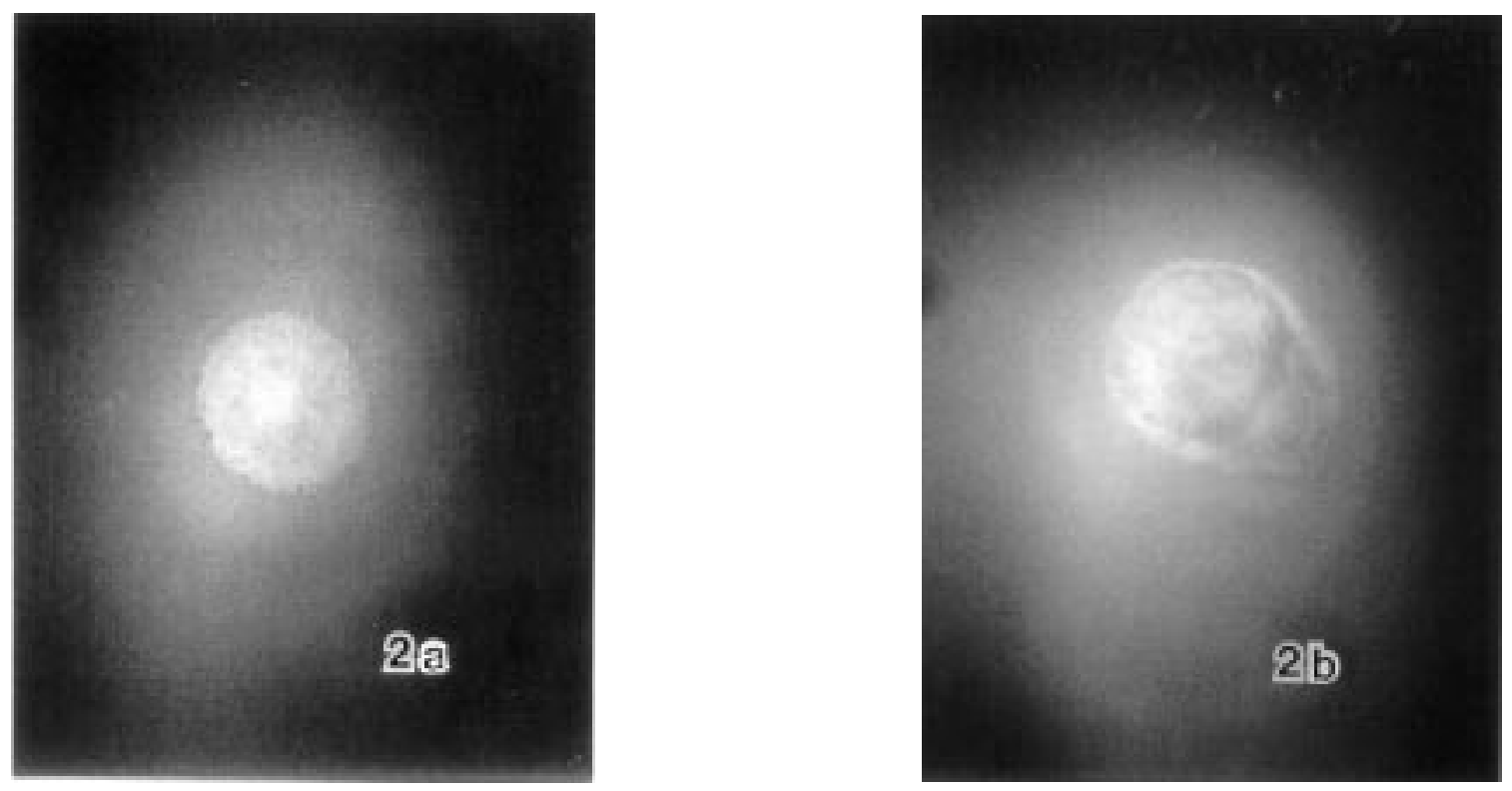

Fig. 2a, b. After 5 days of storage at $18 \mathrm{C}$, some blastoderms show only minor morphological variation when compared to the blastoderm of a fresh laid egg (2a). However, 5 days of cool storage may result in some anomalies, including asymmetry of the blastoderm (2b). 


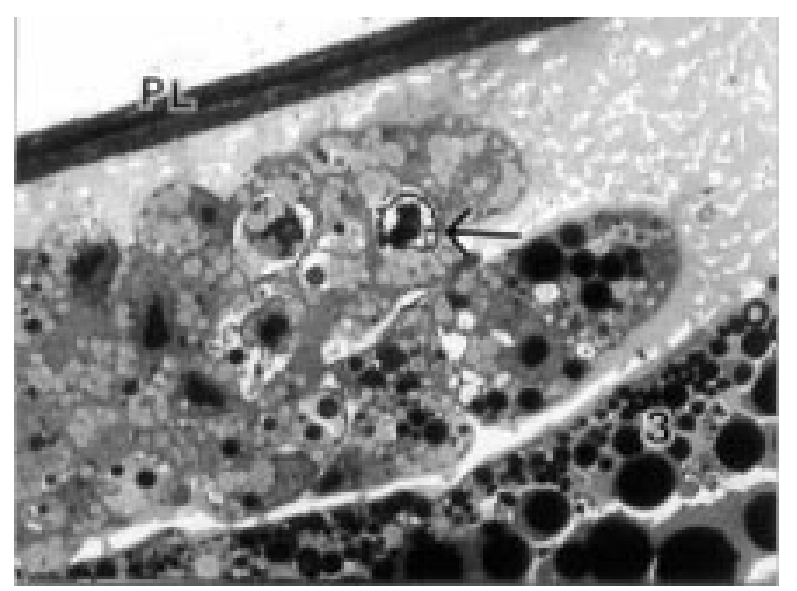

Fig. 3. After 14 days of cool egg storage, the histological appearance of the blastoderm may include such anomalies as reduced extent of the subgerminal cavity, a somewhat disorganized epiblast, and flocculent material surrounding the blastodermal cells. Also seen in this section is a blastodermal cell nucleus (arrow) in the initial stages of chromatin margination, an early sign of apoptosis. The perivitelline layer (PL) is about $5 \mu \mathrm{m}$ in width.

Occasionally pyknotic and apoptotic nuclei were observed (Bakst, personal observations).

Interestingly, blastodermal cell number appears to decrease after the oviposition. Briefly, we examined laid eggs within 1 hour of oviposition and eggs cooled to $18^{\circ} \mathrm{C}$ within 1 hour of oviposition and stored for 2, 4, or 14 days. Blastoderms were then isolated and staged. The blastodermal cells were dispersed, stained with a nuclear fluorescent stain, and counted using a haemocytometer. Blastoderms $(n=43)$ from fresh eggs consisted of about 32,000 $( \pm 3,000)$ cells and 21 of 32 blastoderms were at Stage VII. After 2 days of storage the blastodermal cell number decreased to about $21,500( \pm 2,200)$ cells and about half the blastoderms remained at Stage VII and the other half advanced to Stage VIII After 4 days of storage, the blastodermal cell number was about $19,000( \pm 2,700)$ cells. After 14 days of storage the blastodermal cell number was about 21,000 $( \pm 1,600)$ cells and about half the blastoderms remained at StageVII and the other half advanced to Stage VIII. We suggest that the decrease in blastodermal cell numbers is due to either cell necrosis and apoptosis. Apoptosis has already been reported to be responsible for a $14 \%$ loss of blastodermal cell number soon after oviposition in chicken embryos (Bloom and Muscuarella, 1998). We have immunocytochemically demonstrated apop- tosis in the turkey embryo and it appears to account for some of the blastodermal cell loss following oviposition. But, at this point we are not able to determine the basis for the almost $30 \%$ decrease in blastodermal cell number within 48 hours of oviposition. However, this cell loss is a component of the normal morphogenetic development of the postoviposition turkey blastoderm.

\section{Egg breakout prior to incubation}

Hatchery personnel should be trained to correctly differentiate fertilised from an unfertilised germinal disc (UGD) if fresh egg breakouts are to be used to estimate the true fertility of a flock. True fertility can only be determined by breaking-out fresh eggs prior to incubation or breaking-out the clear eggs from candling, and examining the germinal disc. This permits the precise identification of either a UGD or an early dead embryo, and thus, true fertility. However, differentiation of the UGD from the early dead embryo from the blastoderm, particularly if the egg has been stored for 10 days or greater, can be difficult. We systematically categorized the blastoderms into 11 categories based on the relative density and appearance of the area alba, area pellucida, area opaca, and the periblast (Bakst et al., 1998). Unfertilised germinal discs were divided into 6 categories and were best differentiated from the blastoderms by the presence of vacuoles around a centrally positioned white, dense area. It is recommended that before starting true fertility determinations, one should study the appearance of UGD in eggs from virgin hens. This should then be followed by the examination of the blastoderm in eggs from inseminated hens in order to best appreciate the subtle differences in shape and density of the UGD and blastoderm structural components.

\section{New approaches to fresh egg breakouts}

When problems in hatchability arise in commercial hatcheries, questions must be addressed and remedial action initiated in a timely manner. In contrast to relying on hatch records, candling fertility and the subsequent break-out of clear eggs, and/or the evaluation of hatch residue to determine flock fertility, fresh egg break-outs provide information rapidly on the fertility status of a flock. In doing the latter, the question answered immediately is whether one 
will have high or low true fertility. One relatively new technique, the perivitelline layer (PL)-sperm-hole technique (reviewed by Wishart, 1995) provides additional insight into the status of the egg, by answering the question if sperm actually penetrated the ovum. With this additional information, one is better able to determine if the hatch losses were due to management factors and/or biological factors (low or no mating activity, poor semen quality, or poor artificial insemination techniques) or some combination thereof. Such information will lead to the appropriate management decision to minimize egg losses due to fertility or hatchability problems.

The following represents actual data obtained at commercial broiler breeder and turkey breeder farms after they had experienced either periodic or sustained hatch problems (Bakst, unpublished). The broiler breeder farm was experiencing poor hatches in some pens (1male per 10 hens) but not others. To evaluate the true fertility of eggs from specific pens, a fresh egg breakout program was developed and implemented for 2 weeks. Every second or third day, one or two eggs from each pen was brokenout, the germinal disc status (fertilised, unfertilised, or early dead) identified and the PL-sperm-hole number determined. For all pens, true fertility was $47 \%$. We suggested that in pens with fertility percentages greater than $60 \%$, the male was good (this is supported by the fact that the PL-sperm-hole number was high); alternatively, we suggested that with a percentage of true fertility less than $60 \%$, the male is likely a problem. Since PL-sperm-holes were seen in all fertile eggs in the low true fertility group, it was suggested that while the sperm were viable, sperm transfer may be inefficient during copulation due to anatomical problems [male:female anatomical incompatibilities (personal communication, anonymous)] or the males are not mating as frequently as necessary to maintain high fertility.

Based on such observations, it was suggested that the number of hens per male be reduced, that the males in pens producing less than $60 \%$ fertility should be culled and replaced with new males, or artificial insemination needed to be seriously considered. The latter is the only option if the male and female lines are physically incompatible during mating.

We have had the opportunity to perform fresh egg breakouts on eggs obtained from a turkey breeder company which periodically got reports of low hatchability and high early embryonic mortality in their heavy strains. Eggs from 25 heavy strain hens were examined for the first 5 wk of egg production and from weeks 19 to 24 of egg production. This was replicated. Briefly, in the initial replicate, we could discern no differences in production characteristics between the initial and final weeks of egg production. Eighteen hens had 100\% true fertility; 17 hens had one or more unfertilised or early dead embryos; and, of the 10 hens producing one or more early dead embryos, 3 hens were responsible for $50 \%$ of the early deads. Of the 25 hens in the second replicate, 14 hens had $100 \%$ true fertility; 15 hens had one or more unfertilised or early dead embryos; 11 hens produced one or more unfertilised eggs, with $44 \%$ of the unfertilised eggs derived from just 2 hens. Nine hens produced one or more early deads, with 3 hens responsible for $57 \%$ of the early deads.

There was only minor variation in the stage of embryo development (per Gupta and Bakst, 1993) within and between the two replicates. Whether the slightly more advanced developmental stage (consistently 1-stage) observed in the embryos from incubated eggs laid 21 to 24 weeks of egg production reflects a hen-age effect, a season effect, biological variation, or technical error due the subtle differences between stages have yet to be determined.

Perivitelline layer-sperm-hole numbers were determined only in eggs laid in the late production period and averaged about 22 holes per $5 \mathrm{~mm}^{2}$ of PL overlying the germinal disc. This is excellent. The high frequency of PL sperm holes correlated nicely with the observation that during 21 to 24 weeks of egg production, the eggs laid from 32 of the 50 hens were $100 \%$ true fertility.

To conclude, it is suggested that fresh egg breakouts be used to assess the true fertility of the breeder flock. The benefits of such a routine practice are numerous and include the following: an assessment of flock fertility prior to incubation provides an opportunity to clearly differentiate impact of egg storage and incubation from incubation procedures; if fertility is low, remedial action can be taken in a timely manner; breakouts provide an opportunity to estimate sperm hole frequency in the PL overlying the germinal disc. An excellent review of how to conduct and what to look for in egg breakout sessions before, during and after incubation is provided by Wilson (1995). 


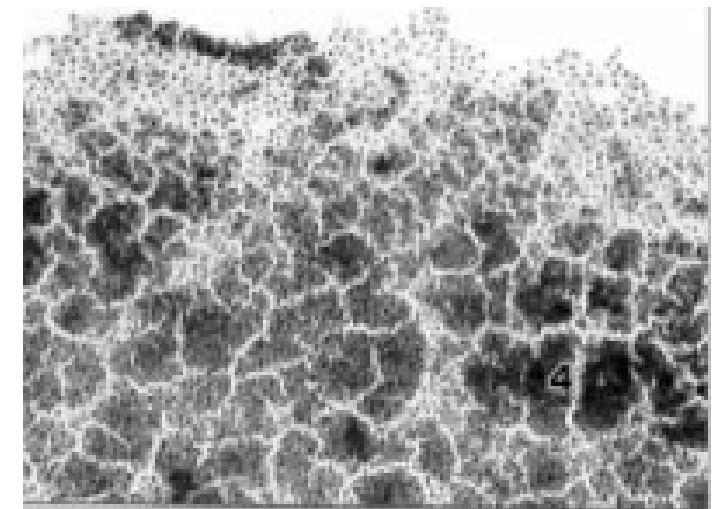

Fig, 4. The edge of an isolated blastoderm removed from a fresh egg reveals extensive reaction product localized to cell nuclei. This is indicative of proliferating cell nuclear antigen and therefore cell proliferation. The attenuated, peripherally located area opaca contrasts with the area pellucida, which is characterized by islands of polyingressing cells.

\section{Immunocytochemistry and application of molecular probes}

We utilized immunocytochemical (ICC) and molecular probes to evaluate the impact of egg storage and incubation at different temperatures. We localized apoptotic cells in the pre-gastrulation blastoderm using a nick translation procedure (using an exogenous polymerase, DNA strand breaks are labelled with a marker nucleotide that is visualized in later steps), thereby identifying apoptotic cells. The localization has been successful but quantification of the positive blastodermal cells remains a problem. Recently, Bloom et al., (1998) and Bloom and Muscarella (1998) have published their work describing apoptosis and factors affecting the rate of apoptosis in pregastrulation chicken embryos.

We are currently in the process of using molecular probes in an effort to identify the impact of cool egg storage for varying periods on blastodermal cell proliferation activity and on stage specific gene expression. Our attempts at using a commercially available antibody to Ki67, which is a cell proliferation-associated antigen, has not been fruitful. Reaction product is discernible in blastodermal whole mounts as well as in dispersed blastodermal cell spreads, but the specificity of the staining is equivocal. While nuclei in the some blastodermal cells were positive, so was the surrounding cytoplasm and/or yolk sphere material. Dispersed, proliferating blastodermal cells in primary cultures exhibited only faint reaction product using anti-Ki67. Conversely, our preliminary observations of the commercially available probe for PCNA, proliferating cell nuclear antigen (formerly called cyclin), provides excellent localization of the nuclei in proliferating blastodermal cells (Figure 4). PCNA is elevated in late $\mathrm{G} 1$, becomes maximal during the $\mathrm{S}$ phase and declines during the G2 and M phases of the cell cycle, and it is continually present in cycling cells. This coupled with the rapid rate of blastodermal cell proliferation, render the vast majority of the cells forming the blastoderm and gastrulating embryo positive for PCNA. In fact, even after 48 hours at $15^{\circ} \mathrm{C}$, PCNA expression in the blastodermal cells is indistinguishable from the PCNA expression of a fresh laid egg. This would suggest that the blastodermal cells at physiological zero are arrested in the G1, S, and G2 phases of the cell cycle.

We are also in the process of using molecular probes in an effort to identify the impact of cool egg storage on stage specific gene expression. We are interested in genes and gene products of developmental importance. Using the probes and methodologies graciously provided by C. Stern (Columbia University, New York) we have successfully localized in the pregastrulating and gastrulating turkey embryo expression of chordin (Figure 5), goosecoid, and $\mathrm{Vgl}$. We will use these probes to determine the impact of various egg handling and storage procedures on their stage specific expression.

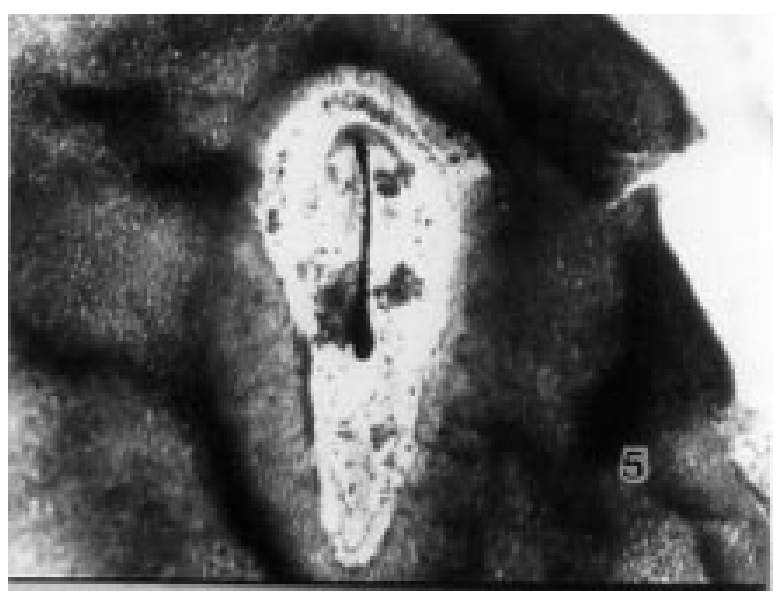

Fig. 5. This turkey embryo [a Stage 7, Hamburger and Hamilton (1951) equivalent] shows intense reaction product for chicken chordin, throughout its primitive streak and Henson's node. The scattered material in the area pellucida is yolk. 


\section{REFERENCES}

Arora, K.L. and Kosin, I.L. (1966a) Changes in the gross morphological appearance of chicken and turkey blastoderms during preincubation storage. Poultry Science, 45:819-25.

Arora, K.L. and Kosin, I.L. (1966b) Developmental responses of early turkey and chicken embryos to preincubation holding of eggs: inter- and intra-species differences. Poultry Science, 45:958-970.

Asmundson, V.S. (1947) Time held prior to incubation and hatchability of turkey eggs. Poultry Science, 26:305-307.

Bakst, M.R. and Gupta, S.K. (1997) Preincubation storage of turkey eggs: impact on the rate of early embryonic development. British Poultry Science 38:376-379.

Bakst, M.R., Gupta, S.K. Potts, W. and Akuffo, V. (1998) Gross appearance of the turkey blastoderm at oviposition. Poultry Science 77:1228-1233.

Bloom, S.E. and Muscarella, D.E. (1998) Stress responses in the early embryo: regulation by pro- and anti-apoptotic cell-death genes. Poultry and Avian Biology Reviews 9:43-55.

Bloom, S.E., Muscarella, D.E., Lee, M.Y. and Rachlinski, M. (1998) Cell death in the avian blastoderm: resistance to stress-induced apoptosis and expression of anti-apoptotic genes. Cell Death and Differentiation 5:529-538.

Butler, D.E. (1991) Egg handling and storage at the farm and hatchery, in: Tullet, S.G.(Ed) Avian Incubation, pp. 195-204 (Boston, Butterworth-Heinemann).

Christensen, V.L. and Bagley, L.G. (1989) Embryology of the turkey, in: C. Nixey and Grey, T.C. (Eds) Recent Advances in Turkey Science, pp. 69-90 (Boston, Butterworths).

Edwards, C.L. (1902) The physiological zero and the index of development for the egg of the domestic fowl, Gallus domesticus. American Journal of Physiology, 6:351-397.

Eyal-Giladi, H. and Kochav, S. (1976) From cleavage to primitive streak formation: A complementary normal table and a new look at first stages of the development of the chick. I. General Morphology. Developmental Biology, 49:321-337.

Fasenko, G.M. Factors influencing embryo and poult viability and growth in stored turkey eggs. PhD Thesis (North Carolina State University, Raleigh, NC)

Fasenko, G.M., Robinson, F.E., Armstrong, J.G., Church, J.S., Hardin, R.T. and Petitte, J.N. (1991) Variability in preincubation embryo development in domestic fowl. 1. Effects of nest holding time and method of egg storage. Poultry Science, 70:1876-1881.

Fasenko, G.M., Robinson, F.E., Hardin, R.T. and Wilson, J.L. (1992) Variability in preincubation embryonic development in domestic fowl. 2. Effects of duration of egg storage period. Poultry Science, 71:2129-2132.
Foulkes, A.G. (1990) The unincubated avian blastoderm - its characterization and an investigation of developmental quiescence. Ph.D. Thesis, (University of Southampton, U.K.)

Funk, E.M. and Billier, H.V. (1944) The minimum temperature for embryonic development in the domestic fowl (Gallus domesticus). Poultry Science, 23:538-540.

Gupta, S.K. and Bakst, M.R. (1993) Turkey embryo staging from cleavage through hypoblast formation. Journal of Morphology, 217:313-325.

Hamburger, V. and Hamilton H.L. (1951) A series of normal stages in the development of the chick embryo. Journal of Morphology, 88:49-92.

Jones, R. (1986) Improve hatchability. Canada Poultryman, May, pp. $20-23$.

Kirk, S., Emmans, G.C., McDonald, R. and Arnot, D. (1980) Factors affecting the hatchability of eggs form broiler breeders. British Poultry Science, 21:37-53.

Landauer, W. (1967) The hatchability of chicken eggs as influenced by environment and heredity. Monogram, 1 - Storrs Agricultural Experimental Station (Connecticut).

Lundy, H. (1969) A review of the effects of temperature, humidity, turning, and gaseous environment in the incubator on the hatchability of the hen's egg, in: T.C. Carter and Freeman, B.M. (Eds) The Fertility and Hatchability of the Hen's Egg, pp. 143-176 Edinburgh, Oliver and Boyd.

Proudfoot, F.G. (1969) The handling and storage of hatching eggs, in: T.C. Carter and Freeman, B.M. (Eds) The Fertility and Hatchability of the Hen's Egg, pp. 127-141 Edinburgh, Oliver and Boyd.

Proudfoot, F.G. and Hamilton, R.M.G. (1990) Care of hatching eggs before incubation. Agriculture Canada Publication $1573 / E$ (Ottawa).

Romanoff, A.L. (1960) The Avian Embryo: Structural and Functional Development. New York, Macmillan Co.

Scott, T.A. and Mackenzie, C.J. (1993). Incidence and classification of early embryonic mortality in broiler breeder chickens. British Poultry Science, 34:459-470.

Wilson, J.L. (1995) Breakout Fertility. Proceedings First International Symposium on the Artificial Insemination of Poultry. Bakst, M.R. and Wishart, G.J. (editors). Published by the Poultry Science Association, Inc. Savoy, IL., Chapter 16, pp. 197-206.

Wishart, G.J. (1995) New approaches to evaluating male and female fertility. Proceedings First International Symposium on the Artificial Insemination of Poultry. Bakst, M.R. and Wishart, G.J. (editors). Published by the Poultry Science Association, Inc. Savoy, IL., Chapter 17, pp. 207-223. 